\title{
Anion Secretion by the Inner Medullary Collecting Duct Evidence for Involvement of the Cystic Fibrosis Transmembrane Conductance Regulator
}

\author{
Russell F. Husted, Kenneth A. Volk, Rita D. Sigmund, and John B. Stokes \\ Laboratory of Epithelial Transport, Department of Internal Medicine, \\ University of Iowa College of Medicine, and Department of Veteran's Affairs, Iowa City, Iowa 52242
}

\begin{abstract}
It is well established that the terminal renal collecting duct is capable of electrogenic $\mathrm{Na}^{+}$absorption. The present experiments examined other active ion transport processes in primary cultures of the rat inner medullary collecting duct. When the amiloride analogue benzamil inhibited electrogenic $\mathrm{Na}^{+}$absorption, cAMP agonists stimulated a transmonolayer short circuit current that was not dependent on the presence of $\mathrm{Na}^{+}$in the apical solution, but was dependent on the presence of $\mathrm{Cl}^{-}$and $\mathrm{HCO}_{3}^{-}$. This current was not inhibited by the loop diuretic bumetanide, but was inhibited by ouabain, an inhibitor of the $\mathrm{Na}^{+} / \mathrm{K}^{+}$pump. The current was reduced by anion transport inhibitors, with a profile similar to that seen for inhibitors of the cystic fibrosis transmembrane conductance regulator (CFTR) $\mathrm{Cl}^{-}$channel. Using several PCR strategies, we demonstrated fragments of the predicted lengths and sequence identity with the rat CFTR. Using whole-cell patch-clamp analysis, we demonstrated a cAMP-stimulated $\mathrm{Cl}^{-}$current with characteristics of the CFTR. We conclude that the rat inner medullary collecting duct has the capacity to secrete anions. It is highly likely that the CFTR $\mathrm{Cl}^{-}$channel is involved in this process. (J. Clin. Invest. 1995. 95:644-650.) Key words: kidney $\cdot \mathrm{Cl}^{-}$secretion $\cdot$ patch clamp $\cdot$ polymerase chain reaction $\cdot$ cell culture
\end{abstract}

\section{Introduction}

The inner medullary collecting duct (IMCD) ${ }^{1}$ is the epithelium that has the final opportunity to modify the composition of the urine before it leaves the kidney. Given this strategically important location, it is not surprising that several humoral and

Address correspondence to John B. Stokes, Department of Internal Medicine, GH E-300, University of Iowa, Iowa City, IA 52242. Phone: 319356-4409; FAX: 319-356-7893.

Received for publication 28 April 1994 and in revised form 25 August 1994.

1. Abbreviations used in this paper: CFTR, cystic fibrosis transmembrane conductance regulator; cpt-cAMP, 8-(4-chlorophenylthio)-adenosine $3^{\prime}: 5$ '-cyclic monophosphate; DIDS, 4,4'-diisothiocyanatostilbene-2,2'disulfonic acid; I $I_{s c}$, short circuit current; IAA-94, 2-[(2-cyclopentyl6,7-dichloro-2,3-dihydro-2-methyl-1-oxo-1H-inden-5-yl)oxy] acetic acid; IBMX, isobutyl methyl xanthine; IMCD, inner medullary collecting duct; NMDG, $N$-methyl-D-glucamine; NPPB, 5-nitro-2-(3-phenylpropylamino)-benzoic acid; $R_{\mathrm{T}}$, transmonolayer electrical resistance.

J. Clin. Invest.

(c) The American Society for Clinical Investigation, Inc. 0021-9738/95/02/0644/07 \$2.00

Volume 95, February 1995, 644-650 autocrine systems have been shown to be involved in the regulation of ion transport (see review by Zeidel [1]). The majority of the efforts at unraveling the regulation of ion transport have been focused on electrogenic $\mathrm{Na}^{+}$transport. This process can be stimulated by steroid hormones $(2,3)$ and inhibited by several peptide hormones (1).

In the course of attempting to understand the nature of the ionic currents in primary cultures of IMCD cells, we have noted that occasionally we could identify a current that was insensitive to some inhibitors of electrogenic $\mathrm{Na}^{+}$transport. The present experiments were undertaken in order to elucidate the nature of this ion transport and to investigate its regulation. The results demonstrate, somewhat unexpectedly, the process of cAMPstimulated, electrogenic anion secretion. This secretory process probably involves the cystic fibrosis transmembrane conductance regulator (CFTR), $\mathrm{a} \mathrm{Cl}^{-}$channel defective in the disease cystic fibrosis.

\section{Methods}

Cell isolation and culture. IMCD cells were isolated from female Wistar rats (75-125 g) maintained on normal rat chow (TekLad, Madison, WI). IMCD cells were prepared using the hypotonic lysis method as described $(2,4)$. Rats were anesthetized with methoxyflurane and decapitated, and the kidneys were removed and rinsed with an isotonic saline solution containing antibiotics. The inner medulla was dissected, minced, and incubated in an isotonic solution containing $0.1 \%$ collagenase for $2-3 \mathrm{~h}$. The incubation was made hypotonic by addition of $2 \mathrm{vol}$ of distilled water containing $10 \mu \mathrm{g} / \mathrm{ml}$ DNase, and cells were recovered after two centrifugation steps. Cells were seeded onto collagen-coated filters (Millicell PCF, Millipore, Bedford, MA) at a seeding density of $\sim 350,000$ cells per $\mathrm{cm}^{2}(2,5)$. Alternatively, cells were seeded on collagen-coated plastic coverslips for analysis by patch clamp. The incubation medium was based on a 1:1 mixture of DME and Ham's F12 with additives as described (5). Antibiotics included norfloxacin (20 $\mu \mathrm{g} / \mathrm{ml})$ for the first 3 days and gentamicin $(50 \mu \mathrm{g} / \mathrm{ml})$ continuously. No serum was used in these cultures; albumin ( $1 \% \mathrm{wt} / \mathrm{vol})$ and cortisol $(50 \mathrm{nM})$ were present for the first $3 \mathrm{~d}$ and then removed. The transmonolayer electrical properties were measured 5 or $6 \mathrm{~d}$ after seeding.

Transepithelial electrical measurements. Measurements of transmonolayer voltage, resistance $\left(R_{T}\right)$, and short circuit current $\left(I_{S C}\right)$ were conducted in custom-designed Ussing chambers constructed to accommodate 12-mm Millicell filter cups (Jim's Instruments, Iowa City, IA). The chambers were water jacketed to $37^{\circ} \mathrm{C}$ and voltage clamped with a University of Iowa device as described $(2,5)$. The solution in which the electrical parameters were measured consisted of $115 \mathrm{mM} \mathrm{NaCl}, 25$ $\mathrm{mM} \mathrm{NaHCO}, 5 \mathrm{mM} \mathrm{KCl}, 5 \mathrm{mM}$ Na Hepes, $5 \mathrm{mM}$ H Hepes, 1.5 $\mathrm{mM} \mathrm{Ca}\left(\mathrm{NO}_{3}\right)_{2}, 1 \mathrm{mM} \mathrm{MgSO}, 1 \mathrm{mM} \mathrm{Na}_{2} \mathrm{HPO}_{4}$, and $5 \mathrm{mM}$ D-glucose. Solutions were continuously gassed, with $5 \% \mathrm{CO}_{2}$ in air so that $\mathrm{pH}$ was 7.4. When ions were substituted, $N$-methyl-D-glucamine (NMDG) replaced $\mathrm{Na}^{+}$, isethionate replaced $\mathrm{Cl}^{-}$, and $\mathrm{Cl}^{-}$or isethionate replaced $\mathrm{HCO}_{3}^{-}$. The $\mathrm{HCO}_{3}^{-}$-free solution was gassed with air. A positive $\mathrm{I}_{\mathrm{SC}}$ value represented a flow of positive charge from the luminal (apical) to the basolateral solution. $R_{T}$ was calculated by imposing a 2-s pulse of 1-5 mV across the monolayer. Values were corrected for the magnitude of the resistance of the filter and the solutions so that $R_{T}$ represented only the resistance of the cell layer. 
Amplification and sequencing of mRNA. Total RNA was isolated from IMCD cells grown on 30-mm Millicell filter cups or excised papilla using the acid guanidinium thiocyanate-phenol-chloroform method of Chomczynski and Sacchi (6). A cDNA library was constructed with IMCD monolayers grown on 27 filters, each of which was exposed to aldosterone for $24 \mathrm{~h}$ before harvest (on day 5 of culture). Poly(A) RNA was extracted using an oligo(dT) column (Poly-A Quick 4; Stratagene, La Jolla, CA), and the library was constructed using the ZAPcDNA/GP-G-11 synthesis kit (Stratagene) according to the manufacturer's instructions.

PCR was conducted on (a) material from the cDNA library, (b) material reverse transcribed from RNA extracted from another group of IMCD cells grown on Millicell filters, and (c) material reverse transcribed from RNA extracted from an intact papilla. Total RNA from primary cultures was prepared for reverse transcription by treatment with RQI DNase (Promega, Madison, WI) to remove contaminating DNA. Reverse transcription was conducted using the GeneAmp Core PCR reagents (Perkin-Elmer Corp., Norwalk, CT) and Maloney murine leukemia virus (M-MLV) reverse transcriptase (Bethesda Research Laboratories, Gaithersburg, MD) on $1 \mu \mathrm{g}$ of RNA, using random hexamer primers. Total RNA from papilla was extracted from tissue that had been rapidly removed, frozen in liquid nitrogen, and stored at $-86^{\circ} \mathrm{C}$. Reverse transcription of this RNA was conducted as for primary cultures except that the DNase treatment step was omitted and the primers included the D-1 oligomer (see the following section) as well as random hexamers.

$5 \mu \mathrm{l}$ of the $20-\mu \mathrm{l}$ reverse transcriptase reaction product was used in the subsequent PCRs. The reaction volume was $25 \mu \mathrm{l}$, the final $\mathrm{Mg}^{2+}$ concentration was $2 \mathrm{mM}$, and the primer concentrations were $\sim 0.5$ $\mu \mathrm{M}$. When the cDNA library was used for PCR, $2 \mu \mathrm{l}$ of starting material $\left(\sim 7 \times 10^{7} \mathrm{pfu} / \mu \mathrm{l}\right)$ was boiled for $5 \mathrm{~min}$ before proceeding to PCR. 30 cycles of 1 min each were routinely used, with annealing and extension temperatures of $66^{\circ} \mathrm{C}$ and $72^{\circ} \mathrm{C}$, respectively.

Primers for amplifying the CFTR were constructed from the published rat sequence (7). They were designed to amplify sequences that begin in exon 13 and end in exon 14b. Two upstream and two downstream primers were chosen with the help of the Primer computer program (Whitehead Institute, Cambridge, MA) to provide maximum flexibility in generating different length products and for use in "nesting" reactions. Upstream primers were 5'-GCAAAACTAGGATTCTGGTCACATCTAAAATGG-3' (U-1) and 5'-CGCAGGTTCTCAGTGGACGATGCC-3' (U-2); downstream primers were 5'-ACCACAACACAAATAAAGAAGCAGCCACC-3' (D-1) and 5'-CCTCAACCAGAAAAACCAGCACGCA-3' (D-2). The U-1 and D-1 (external) primer pair would produce a CFTR product of $843 \mathrm{bp}$, and the U-2 and D-2 (internal) primer pair would produce a product of $606 \mathrm{bp}$. PCRamplified products were separated by electrophoresis through a $1.8 \%$ agarose gel and stained with ethidium bromide.

The fully nested PCR product from the papilla was prepared for sequencing by applying $15 \mu \mathrm{l}$ of the reaction mixture to a microconcentrator (Microcon-100; Amicon, Beverly, MA). A total volume of $6 \mathrm{ml}$ of ultrapure water was sequentially. applied and centrifuged through the filter unit at $500 \mathrm{~g}$ for $15 \mathrm{~min}$. Of the $50 \mu \mathrm{l}$ of concentrate recovered, $5 \mu \mathrm{l}$ was sequenced by fluorescent labeling of dideoxynucleotide chain termination (373A automated DNA sequencer; Applied Biosystems, Foster City, CA) in the University of Iowa DNA core facility.

Patch-clamp analysis. Cells for whole-cell patch clamp were seeded onto collagen-coated plastic coverslips. By inspection, cells were usually confluent on day 3 , at which time $1 \mathrm{mM} 4$-methylumbelliferyl- $\beta$-Dxyloside and $2.5 \mathrm{mM} \mathrm{D}(+)$-galactosamine were added to the medium. These agents have been shown to inhibit proteoglycan synthesis $(8$, 9). Pilot studies conducted in this lab have demonstrated a marked improvement in the rate of successful seal formation in IMCD cells so treated. These agents do not impair the qualitative response of the monolayers to the maneuvers reported in these studies (data not shown).

To ensure electrical isolation, cells were treated with a $\mathrm{Ca}^{2+}$-free medium for 30-60 min before use so that junctional complexes and intercellular connections were minimized and cells were spherical. Cell isolation was ascertained by inspection $(\times 600)$. Electrical isolation was also documented. After the whole-cell configuration was achieved, a capacitative current transient was elicited with a $10-\mathrm{mV}$ depolarization. A single exponential with a time constant of $\sim 0.1 \mathrm{~ms}$ was taken as evidence of cell isolation. When the cells were not separated with the $\mathrm{Ca}^{2+}$-free medium, this current transient often had at least two exponential components with time constants as high as hundreds of milliseconds. Series resistance and whole-cell capacitance were calculated by fitting the capacitative transient elicited with $10-\mathrm{mV}$ voltage steps from a holding potential of $-60 \mathrm{mV}(10)$. The average values for 17 cells were $4.21 \pm 0.43 \mathrm{M} \Omega$ and $24.8 \pm 1.4 \mathrm{pF}$, respectively. The normal bath solution contained $140 \mathrm{mM} \mathrm{NaCl}, 4 \mathrm{mM} \mathrm{NaOH}, 4.5 \mathrm{mM} \mathrm{KCl}, 2.5 \mathrm{mM} \mathrm{CaCl}_{2}$, $1 \mathrm{mM} \mathrm{MgCl}, 10 \mathrm{mM}$ H Hepes, $5 \mathrm{mM}$ glucose, and $20 \mathrm{mM}$ sucrose, pH 7.4, osmolality $=320 \mathrm{mOsm} / \mathrm{kg}$. The $\mathrm{Ca}^{2+}$-free medium was the normal bath solution with $\mathrm{Ca}^{2+}$ and $\mathrm{Mg}^{2+}$ salts removed and $1 \mathrm{mM}$ EGTA added. All seals were initially made in the normal $\left(\mathrm{Ca}^{2+}-\right.$ containing) bath solution after a 15 -min recovery from dissociation. This maneuver was necessary because the seal formation rate in NMDG solution or $\mathrm{Ca}^{2+}$-free solution was unacceptably low. In some experiments, the bath was changed to one in which $\mathrm{Na}^{+}$and $\mathrm{K}^{+}$were replaced by NMDG. The NMDG bath solution contained $200 \mathrm{mM}$ NMDG, 150 $\mathrm{mM} \mathrm{HCl}, 1 \mathrm{mM} \mathrm{CaCl}, 1 \mathrm{mM} \mathrm{MgCl} 2,10 \mathrm{mM}$ H Hepes, $5 \mathrm{mM}$ Dglucose, and $20 \mathrm{mM}$ sucrose, $\mathrm{pH} \mathrm{7.35}$, osmolality $=325 \mathrm{mOsm} / \mathrm{kg}$. The pipette solution always contained $194 \mathrm{mM} \mathrm{NMDG}, 140 \mathrm{mM} \mathrm{HCl}$, $1 \mathrm{mM}$ EGTA, $10 \mathrm{mM}$ H Hepes, and $3.2 \mathrm{mM} \mathrm{MgATP}, \mathrm{pH} 7.2$, osmolality $=276 \mathrm{mOsm} / \mathrm{kg}$. Extensive preliminary experimentation demonstrated that the osmotic difference between the pipette and bath solution was necessary to minimize volume-activated currents $(11,12)$. Pipettes used to obtain the whole-cell configuration were constructed from borosilicate glass capillaries (VWR Scientific, West Chester, PA) using a micropipette puller (P-87 Flaming-Brown, Sutter Instrument, San Rafael, CA). The pipettes were coated with a layer of Sylgard 184 (Dow Corning, Midland, MI) and fire polished. These pipettes had resistances of 2-4 $\mathrm{M} \Omega$ when filled with the pipette solution. Seals obtained under these conditions in excess of $10 \mathrm{G} \Omega$ were considered acceptable. Membrane patches were ruptured with suction.

Voltage-clamp command voltages were generated and membrane currents were acquired with a patch-clamp amplifier (Axopatch 200, Axon Instruments, Burlingame, CA) under the control of pCLAMP software (Axon Instruments). The Axon CV201 headstage was controlled by a piezo drive patch-clamp micromanipulator (PCS-1000, Burleigh Instruments, Fishers, NY). Bath temperature was controlled to $35^{\circ} \mathrm{C}$ by a microchamber thermal stage and digital temperature controller (Brook Industries, Lake Villa, IL) mounted on an IMT-2 inverted microscope, (Olympus Corp., Lake Success, NY). Electrical signals were digitized using an analog-to-digital converter (Labmaster TM 125, Axon Instruments) and stored on the hard disk of an IBM-compatible 486 personal computer.

Materials. Rats were purchased from Harlan Sprague Dawley, Inc. (Indianapolis, IN). Medium and gentamicin were from the University of Iowa Cancer Center, albumin was from Intergen (Purchase, NY), 2- [(2cyclopentyl-6,7-dichloro-2,3-dihydro-2-methyl-1-oxo-1H-inden-5-yl) oxy] acetic acid (IAA-94) was from RBI (Natick, MA), 5-nitro-2-(3phenylpropylamino)-benzoic acid (NPPB) was a gift from Hoechst (Frankfurt, Germany), and benzamil was a gift from Merck (West Point, PA). All other chemicals were purchased from Sigma Chemical Co. (St. Louis, MO). Stock solutions of benzamil, NPPB, and glybenclamide were prepared in DMSO at 1,000 times the desired final concentration. Similar stocks of forskolin, isobutylmethylxanthine (IBMX), bumetanide, and IAA-94 were prepared in ethanol. These stocks were added to the solutions bathing the monolayers. The final carrier concentration of $0.1 \%$ did not significantly affect the $I_{S C}$ or $R_{\mathrm{T}} \cdot 4,4^{\prime}$-Diisothiocyanatostilbene2,2'-disulfonic acid (DIDS) was either freshly prepared as a DMSO stock or made as a $2 \times$ stock in the appropriate solution. The response was not different. Ouabain and 8-(4-chlorophenylthio)-adenosine $3^{\prime}: 5^{\prime}$-cyclic monophosphate (cpt-cAMP) were prepared as $10 \mathrm{mM}$ stocks in the appropriate solutions.

Statistics. Values are expressed as mean \pm SEM. Analysis was conducted using Student's unpaired $t$ test or analysis of variance and Newman-Keuls multiple rank test as indicated. 


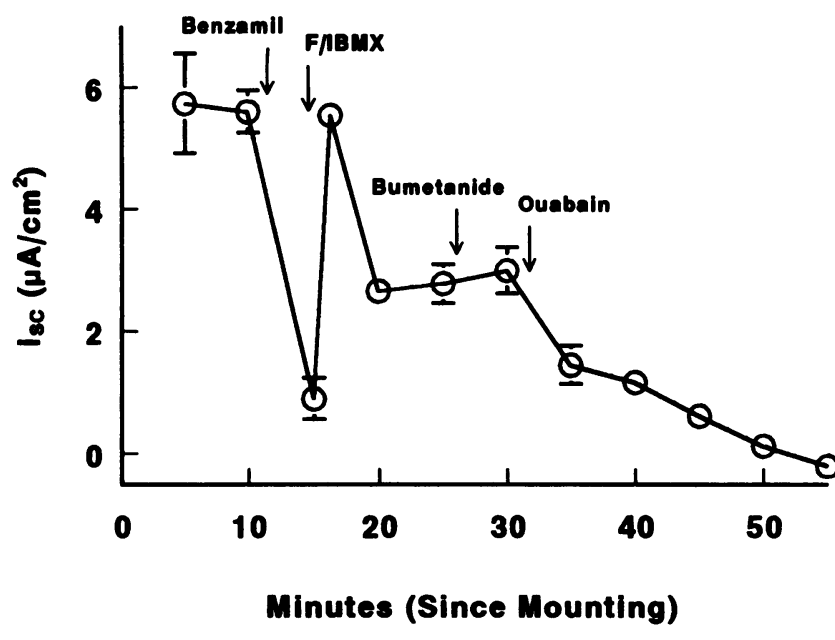

Figure 1. Effects of cAMP and transport inhibitors on $\mathrm{I}_{\mathrm{SC}}$ of primary culture of IMCD cell monolayer. Addition of $10 \mu \mathrm{M}$ benzamil (to apical solution), $10 \mu \mathrm{M}$ forskolin and $100 \mu \mathrm{M}$ IBMX (F/IBMX, to apical and basolateral solutions), $100 \mu \mathrm{M}$ bumetanide (basolateral), and $2 \mathrm{mM}$ ouabain (basolateral). Values are means $( \pm$ SEM) of four monolayers from a representative isolation. Similar data were obtained using the permeant cAMP analog cpt-cAMP $(100 \mu \mathrm{M})$.

\section{Results}

The effects of maneuvers used to elucidate the nature of $I_{S C}$ are depicted in Fig. 1. $\mathrm{I}_{\mathrm{SC}}$ achieved a steady state within 5-10 min after mounting; the majority of $\mathrm{I}_{\mathrm{SC}}$ was inhibited (within $10 \mathrm{~s}$ ) by $10 \mu \mathrm{M}$ benzamil added to the apical solution. This response to the specific epithelial $\mathrm{Na}^{+}$channel blocker (13) is similar to what we have previously reported $(2,3)$. We noted that in solutions containing $\mathrm{HCO}_{3}^{-}$, benzamil was less likely to produce complete inhibition of $\mathrm{I}_{\mathrm{SC}}$ compared with monolayers bathed in a non- $\mathrm{HCO}_{3}{ }^{-}$, Hepes-buffered solution (2). In the continued presence of benzamil, addition of the cAMP agonists forskolin $(10 \mu \mathrm{M})$ and IBMX $(100 \mu \mathrm{M})$ produced a prompt increase in $I_{S C}$. There was a transient component that subsequently stabilized. This $\mathrm{I}_{\mathrm{SC}}$ was insensitive to $100 \mu \mathrm{M}$ bumetanide, an inhibitor of the $\mathrm{Na}^{+} / \mathrm{K}^{+} / 2 \mathrm{Cl}^{-}$exchanger, but was inhibited by $2 \mathrm{mM}$ ouabain, a specific inhibitor of the $\mathrm{Na}^{+} / \mathrm{K}^{+}$pump. Ouabain's action was biphasic: $50-60 \%$ of the effect was evident within the first minute, whereas the remaining $I_{S C}$ was reduced to 0 over 20-30 min. The $R_{T}$ tended to increase throughout the course of the experiment, and against this somewhat variable background, the effect of cAMP agonists on $R_{T}$ was not statistically significant.

Ionic dependence of $I_{S C}$. The direction of the $I_{S C}$ stimulated by cAMP indicated either net absorption (translocation from apical to basolateral ) of a cation (s) or secretion of an anion( $s$ ). We therefore performed substitution experiments to determine the ionic dependence of the cAMP-stimulated $\mathrm{I}_{\mathrm{SC}}$. We report the effects of $10 \mu \mathrm{M}$ forskolin and $100 \mu \mathrm{M}$ IBMX; however, either cpt-cAMP or the forskolin/IBMX combination produced the same effect, and they were not additive.

The responses to cAMP agonists when isethionate was (bilaterally) substituted for $\mathrm{Cl}^{-}, \mathrm{Cl}^{-}$for $\mathrm{HCO}_{3}^{-}$, or isethionate for $\mathrm{Cl}^{-}$and $\mathrm{HCO}_{3}^{-}$are shown in Fig. 2. Removal of $\mathrm{Cl}^{-}$and/or $\mathrm{HCO}_{3}^{-}$greatly blunted the response to cAMP compared with control monolayers from the same isolation. Anion substitution also tended to reduce the basal $\mathbf{I}_{\mathbf{S C}}$ (determined after benzamil),

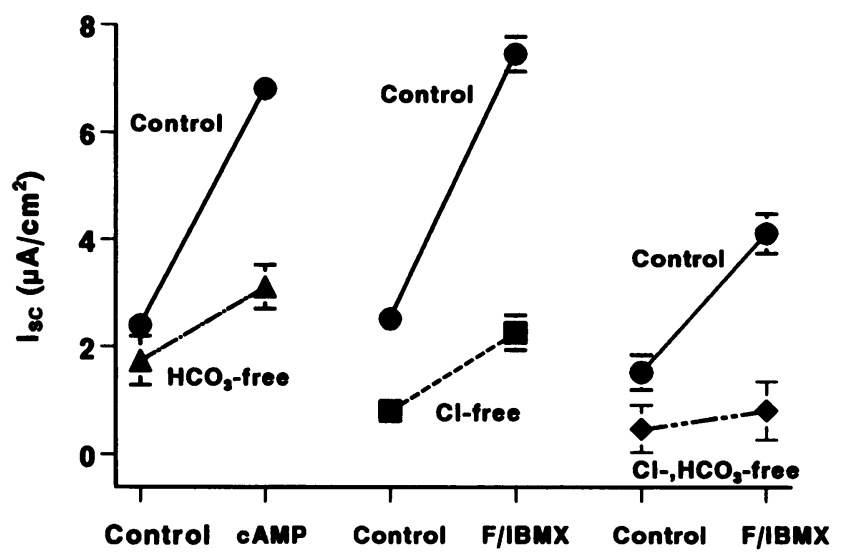

Figure 2. Anion dependence of $\mathrm{I}_{\mathrm{sc}}$. Bilateral removal of either $\mathrm{HCO}_{3}{ }^{-}$ $\left(\mathrm{Cl}^{-}\right.$substitution, left) or $\mathrm{Cl}^{-}$(isethionate substitution, middle), or both $\mathrm{Cl}^{-}$and $\mathrm{HCO}_{3}^{-}$(isethionate substitution, right) greatly blunted the ability of cAMP agonists to stimulate $\mathrm{I}_{\mathrm{SC}}$. Control values are from the same isolation measured in standard $\mathrm{HCO}_{3}{ }^{-}$-containing solutions after addition of $10 \mu \mathrm{M}$ benzamil to the apical solution to inhibit $\mathrm{Na}^{+}$transport. Reported values are steady state. $n=4-8$ monolayers for each group. $P<0.001$ by unpaired analysis for each set of substitutions compared with controls.

although this effect was small. These results support the view that the cAMP-stimulated $\mathrm{I}_{\mathrm{SC}}$ was anion secretion. However, they do not completely eliminate the possibility that $\mathrm{I}_{\mathrm{SC}}$ could be an anion-dependent, benzamil-insensitive $\mathrm{Na}^{+}$absorption. To examine this possibility, we removed $\mathrm{Na}^{+}$from the apical solution (NMDG replacement) and added cAMP agonists. The baseline $\mathrm{I}_{\mathrm{SC}}$ with asymmetrical solutions is larger than with symmetrical solutions in the presence of benzamil because of the diffusion current. However, as shown in Fig. 3, removal of apical $\mathrm{Na}^{+}$did not reduce the magnitude of the cAMP-stimulated $\mathrm{I}_{\mathrm{SC}}$; if anything, the stimulation was larger $(P<0.005)$. Similar results were obtained when both $\mathrm{Na}^{+}$and $\mathrm{K}^{+}$were removed (data not shown). These results support the idea that the cAMP-stimulated $\mathrm{I}_{\mathrm{SC}}$ reflects anion secretion and not cation absorption.

Inhibitors of anion secretion. The presence of an anion secretory $\mathrm{I}_{\mathrm{SC}}$ implicates an anion-conductive pathway on the

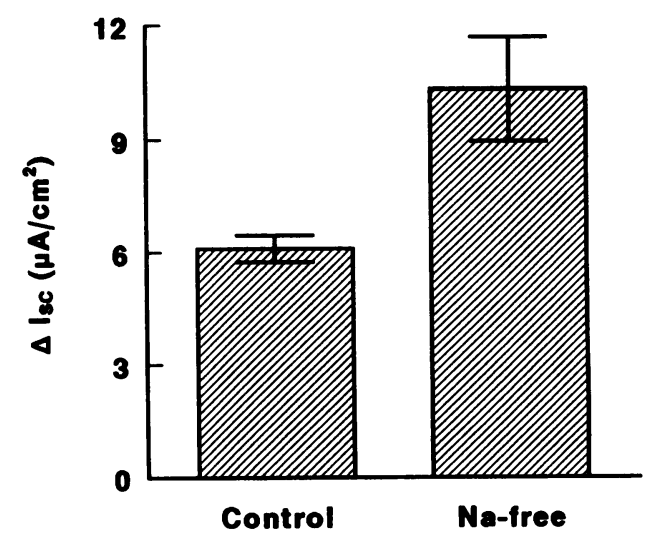

Figure 3. Increase in $\mathrm{I}_{\mathrm{SC}}$ in response to cAMP agonists in monolayers in which apical solution $\mathrm{Na}^{+}$was replaced with NMDG. Control monolayers contained normal solutions to which $10 \mu \mathrm{M}$ benzamil was added to the apical side. $n=6$ monolayers each. 


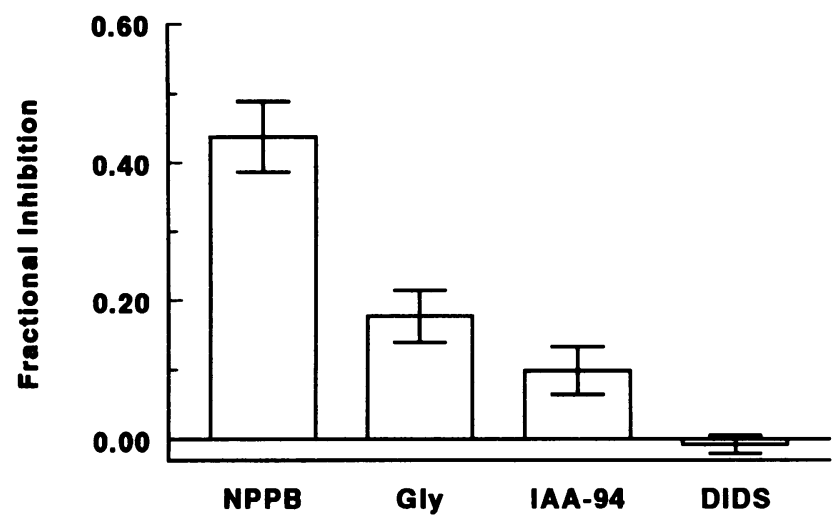

Figure 4. Effect of inhibitors of anion transport on cAMP-stimulated $I_{\text {SC }}$. Fractional inhibition of $I_{S C}$ was calculated using the steady-state value and the value $10 \mathrm{~min}$ after addition of the inhibitor. All inhibitors were added to the apical solution to make a final concentration of 100 $\mu \mathrm{M}$ except DIDS. DIDS was added to $500 \mu \mathrm{M} . n=6-12$ monolayers from two to three isolations for each inhibitor. Effects of inhibitors were different by ANOVA $(P<0.01)$. NPPB $>$ glybenclamide (Gly); IAA$94>$ DIDS by Newman-Keuls at $P<0.05$.

apical membrane. One possible candidate for a cAMP-stimulated anion conductance is the CFTR $\mathrm{Cl}^{-}$channel (14). The possibility that anion secretion by these IMCD cells proceeds via the CFTR on the apical membrane can be evaluated by examining the actions of inhibitors. Although most inhibitors of anion transport lack specificity, their effects on the CFTR have been studied sufficiently that a characteristic fingerprint has been established. All inhibitors were added to the apical solution in the presence of $10 \mu \mathrm{M}$ benzamil so that confounding effects of changes in $\mathrm{Na}^{+}$transport on $\mathrm{I}_{\mathrm{SC}}$ would be eliminated.

Fig. 4 shows the fractional inhibition of the cAMP-stimulated $\mathbf{I}_{\mathrm{SC}}$ of selected anion channel inhibitors. The most potent agent was NPPB; it had a significantly greater effect from the apical surface compared with the basolateral surface (data not shown). However, even at this relatively high concentration, NPPB did not completely inhibit $\mathrm{I}_{\mathrm{SC}}$, an observation consistent with its effect on the CFTR. Glybenclamide, best known as an inhibitor of a class of ATP-sensitive $\mathrm{K}^{+}$channels, has been recently discovered to inhibit the CFTR in excised membrane patches (15). In these IMCD cells it had a modest inhibitory effect. We used IAA-94 and DIDS because these agents characteristically have small or no effect on the CFTR. This rank order of potency of these agents is consistent with inhibition of the CFTR (14).

CFTR $m R N A$. Because the inhibitor experiments suggested the involvement of the CFTR in anion secretion, we sought to detect molecular evidence for its presence in IMCD cells. We chose PCR strategies for demonstrating CFTR mRNA. This approach was selected over Northern analysis or immunoblotting because CFTR mRNA and protein are probably in low abundance. Even in epithelia, where CFTR-mediated $\mathrm{Cl}^{-}$secretion is vigorous, CFTR mRNA and protein can be difficult to demonstrate. In IMCD cells, in which the magnitude of CAMPstimulated $\mathrm{Cl}^{-}$secretion is smaller than in some other $\mathrm{Cl}^{-}$. secreting tissues, we anticipated that we would require a sensitive assay for biochemical detection. We designed the PCR primers to amplify across an intron, thereby excluding the possibility that products of the expected lengths would have resulted from amplified DNA.

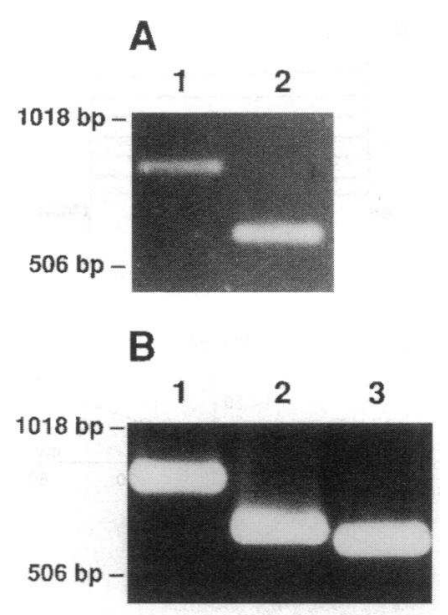

Figure 5. Ethidium bromidestained agarose gel of PCR products demonstrating CFTR mRNA. (A) PCR products from the IMCD library show products from U-1 and D-2 primers (lane 1) and U-2 and D-2 primers (lane 2) that are not different from the predicted lengths of $816 \mathrm{bp}$ and $606 \mathrm{bp}$, respectively. (B) PCR products from reversetranscribed RNA from primary cultures. Nested and seminested PCR products amplified using $\mathrm{U}-1$ and $\mathrm{D}-1$ primers initially. Products from $\mathrm{U}-1$ and $\mathrm{D}$ 2 (lane 1 ), U-2 and D-1 (lane 2), and U-2 and D-2 (lane 3) are not different from the pre-

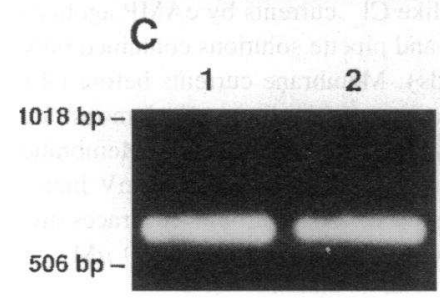
dicted lengths of $816 \mathrm{bp}, 633 \mathrm{bp}$ and $606 \mathrm{bp}$, respectively. $(C)$ PCR products from reversetranscribed RNA from primary cultures (lane 2) and whole papilla (lane 1). Initial amplification was with U-1 and D-1 primers; subsequent reaction was with U-2 and D-2 primers (fully nested reactions). Lanes 1 (papilla) and 2 (cultured cells) show product size not different from the predicted length of $606 \mathrm{bp}$. The sequence of product in lane 1 was identical to the reported sequence of the rat CFTR (7). Indicated lengths denote DNA standards.

We used three different PCR approaches. First, we used material from a cDNA library constructed from primary cultures of IMCD cells. The results of this PCR amplification are shown in Fig. 5 A. The U-1 and D-2 primer pair and the U-2 and D2 primer pair produced products that were not different from the predicted lengths of 816 and $606 \mathrm{bp}$, respectively. In the second approach, we used cDNA from a reverse transcription reaction using primary cultures of IMCD cells grown identically to those used in the $\mathrm{I}_{\mathrm{SC}}$ and inhibitor studies. The results of this approach are displayed in Fig. 5 B. First we amplified the cDNA using the U-1 and D-1 primers. We subsequently amplified this product with U-1 and D-2 or U-2 and D-1 (semi-nested) or with U-2 and D-2 (fully nested). These reactions yielded products that were not different from the predicted lengths. Products were not detected when reverse transcriptase was omitted from the initial reaction.

In the third approach, we amplified reverse-transcribed material from primary cultures and whole papilla. The major purpose of this experiment was to determine whether the PCR products amplified from cultured cells could be amplified from native tissue. Using the fully nested protocol, we found that the PCR product in cultured IMCD cells and papilla migrated similarly on an agarose gel (Fig. $5 C$ ). The lengths of these products were not different from the predicted length of 606 bp. As a final confirmation, we sequenced the PCR product from the papilla. There was $100 \%$ identity with the published sequence for this region of the rat CFTR (7). From the results of the PCR amplifications involving the cDNA library and the PCR nested reactions, we conclude that CFTR mRNA is present in primary cultures of IMCD cells and in the native papilla.

Functional evidence of the CFTR. The results of the inhibitor studies on the cAMP-stimulated $\mathrm{I}_{\mathrm{SC}}$ together with the PCR 


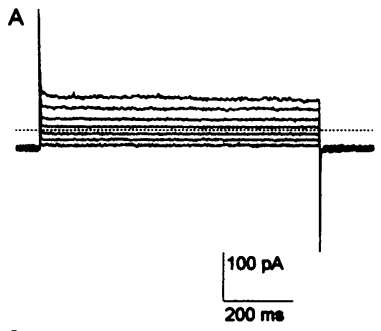

C

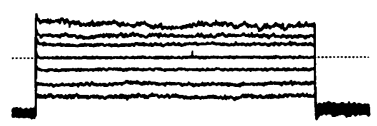

B

D

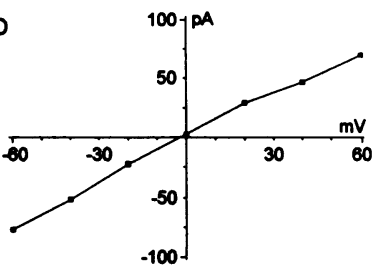

Figure 6. Demonstration of CFTR-like $\mathrm{Cl}^{-}$currents by cAMP agonists using whole-cell patch clamp. Bath and pipette solutions contained only $\mathrm{Cl}^{-}$as a permeant ion (see Methods). Membrane currents before $(A)$ and after $(B)$ cAMP agonists. The subtracted currents $(C)$ demonstrate linearity, as shown in the current-voltage relationship $(D)$. Membrane voltage was held at $-80 \mathrm{mV}$ and stepped to $\pm 60 \mathrm{mV}$ in $20-\mathrm{mV}$ increments for $800 \mathrm{~ms}$. Dashed lines represent 0 current; current traces are superimposed. cAMP agonists included $10 \mu \mathrm{M}$ forskolin, $100 \mu \mathrm{M}$ IBMX, and $500 \mu \mathrm{M}$ cpt-cAMP.

results led us to suspect that the CFTR was functionally expressed. We therefore conducted whole-cell patch-clamp experiments looking for evidence of a cAMP-induced, nonrectifying $\mathrm{Cl}^{-}$current. Fig. 6 shows an example of such a current. Under the conditions used for these experiments and before adding cAMP agonists, the $\mathrm{Cl}^{-}$current was small (Fig. $6 \mathrm{~A}$ ); after cAMP addition, the current was markedly enhanced (Fig. $6 \mathrm{~B}$ ). The subtracted current (Fig. $6 C$ ) showed a linear currentvoltage relationship (Fig. $6 \mathrm{D}$ ), typical of the CFTR. An example of the time course of the response to cAMP agonists is shown in Fig. 7. It is clear that cAMP agonists produced a reversible increase in the whole-cell $\mathrm{Cl}^{-}$current within the time frame similar to that of the $I_{S C}$ response demonstrated in the monolayers (Fig. 1).

The magnitude of the response to cAMP was $\sim 100 \mathrm{pA}$ at voltages of $\pm 60 \mathrm{mV}$. Of 13 successful seals demonstrating small, stable currents before cAMP agonists, 8 cells showed a clear increase in the current. This cAMP-stimulated current was seen with both the $\mathrm{Na}^{+}$-containing (3/5) and the $\mathrm{Na}^{+}$-free (5/ 8 ) bath solutions. The majority of the cAMP-stimulated current demonstrated a linear current-voltage relationship. A few cells displayed a mild inward or outward rectification. These results demonstrate that cAMP-stimulated $\mathrm{Cl}^{-}$currents are present in IMCD cells and that in most (if not all) cases the nature of the current-voltage relationship is that which would be expected for the CFTR.

\section{Discussion}

The results of these experiments demonstrate that cAMP agonists stimulate active, electrogenic ion transport by primary cultures of IMCD cells. The energy for this transport is, directly or indirectly, derived from the $\mathrm{Na}^{+} / \mathrm{K}^{+}$pump because, following exposure to ouabain (a specific inhibitor of the pump), $I_{S C}$ is reduced to 0 . The cAMP-stimulated $\mathrm{I}_{\mathrm{SC}}$ is largely dependent on the presence of $\mathrm{Cl}^{-}$and $\mathrm{HCO}_{3}^{-}$and is not reduced by removing

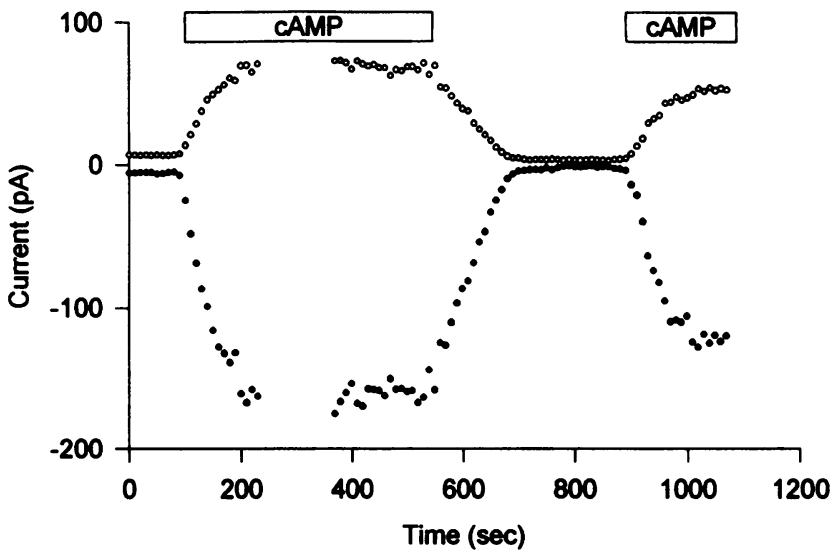

Figure 7. Time course of cAMP action on whole-cell $\mathrm{Cl}^{-}$currents. Conditions for this experiment were similar to those in Fig. 6. Every $10 \mathrm{~s}$ membrane voltage was stepped from -80 (closed circles) to -40 $\mathrm{mV}$ (open circles) for $800 \mathrm{~ms}$ cAMP indicates application of the combination of agonists used in Fig. 6.

$\mathrm{Na}^{+}$or $\mathrm{K}^{+}$from the apical solution. These ion substitution experiments demonstrate that this cAMP-stimulated $\mathrm{I}_{\mathrm{sc}}$ reflects secretion of anions.

The most extensively studied anion $\left(\mathrm{Cl}^{-}\right)$-secreting epithelia are those exemplified by the mammalian intestine and airways. These epithelia have a basolateral entry process that is inhibited by loop diuretics such as furosemide and bumetanide. There is good reason to believe that this entry pathway is a $\mathrm{Na}^{+} / \mathrm{K}^{+} / 2 \mathrm{Cl}^{-}$cotransporter (16). $\mathrm{Cl}^{-}$secretion is completed by its translocation across the apical membrane via a conductive pathway (channel). In many $\mathrm{Cl}^{-}$-secreting epithelia, this channel appears to be the CFTR (14).

The CFTR in the IMCD. The data presented in this manuscript provide functional, pharmacological, and biochemical evidence for a role for the CFTR in the process of cAMP-stimulated anion secretion. The first indication that the CFTR might be functional in IMCD cells comes from the demonstration that cAMP agonists stimulate a transepithelial anion current (Figs. 1-3). cAMP-stimulated $\mathrm{Cl}^{-}$secretion is a widely distributed and intensively studied process. In epithelial cells, where it has been studied extensively, such as in airway and intestinal cells, the CFTR plays an important role in the secretory process (14).

The whole-cell patch-clamp data provide additional functional evidence for the CFTR in IMCD cells. The conditions were selected to isolate $\mathrm{Cl}^{-}$currents; in most of the experiments, $\mathrm{Cl}^{-}$was the only permeant ion. The fact that the current reversed at $0 \mathrm{mV}$ (Fig. 6) either in the presence or absence of $\mathrm{Na}^{+}$in the bath supports the idea that $\mathrm{Na}^{+}$currents were negligible. The demonstration of a cAMP-activated $\mathrm{Cl}^{-}$current with a linear current-voltage relationship provides strong evidence for the presence of the CFTR. There are no other $\mathrm{Cl}^{-}$currents that are known to behave in this fashion $(14,17)$.

The pharmacological evidence for the CFTR consists of the actions of a group of anion transport inhibitors added to the apical solution (Fig. 4). It is increasingly apparent that anion transport inhibitors lack specificity, but their relative potency in inhibiting the CFTR $\mathrm{Cl}^{-}$channel is generally acknowledged. The classes of inhibitors exemplified by NPPB are relatively potent inhibitors of most $\mathrm{Cl}^{-}$channels. They are less potent inhibitors of the CFTR, but of the agents known to inhibit the CFTR, this class is the most potent $(14,17)$. In contrast, DIDS 
and IAA-94 are poor inhibitors of the CFTR, whereas they are good inhibitors of other kinds of $\mathrm{Cl}^{-}$channels $(14,18)$. The fact that glybenclamide, an inhibitor of a class of ATP-sensitive $\mathrm{K}^{+}$channels, also (partially) inhibits the CFTR (15) and the cAMP-stimulated anion currents of IMCD cells further supports a role for the CFTR in IMCD cells. The inhibitor profile for anion secretion by IMCD is thus consistent with a major role for the CFTR in cAMP-stimulated anion secretion.

The biochemical evidence for the CFTR in IMCD cells consists of the PCR amplification of material from primary cultures of IMCD cells and from intact papilla. Obtaining the predicted length fragments by using two semi-nested and a fully nested approach from two different sources of cultured cells (Fig. 5) provides strong evidence that CFTR mRNA is present in these cells. The identification of a PCR product from papilla that has the same length as the product from cultured cells (Fig. 5) and the identical sequence as the rat CFTR (7) solidifies the conclusion that IMCD cells contain mRNA for the CFTR.

Based on this evidence, we conclude that anion secretion by the cultured rat IMCD cell proceeds via the CFTR located on the apical membrane. The localization of the CFTR to the apical membrane can be inferred from the presence of electrogenic anion transport and from the actions of inhibitors from the apical solution. All current models of electrogenic anion secretion require an apical membrane anion-conductive pathway or channel. The CFTR is normally expressed on the apical membrane of $\mathrm{Cl}^{-}$-secreting epithelial cells. We wish to point out two qualifications to our conclusion. First, we cannot be certain that all of the CFTR is expressed on the apical membrane; whole-cell patch-clamp experiments do not permit localization. However, the pharmacological experiments strongly support an apical membrane localization. Second, we cannot be certain that the CFTR is the only type of $\mathrm{Cl}^{-}$channel on the apical membrane. Whether apical membrane CFTR can account for all $\mathrm{Cl}^{-}$secretion even in cells that have been extensively studied is, at present, uncertain (14). The possibility that other kinds of anion channels are present in the apical membrane of IMCD cells will require further experimentation.

The IMCD demonstrates some important functional differences from the widely studied $\mathrm{Cl}^{-}$-secreting cells of the airways and intestine. The most striking difference is the lack of effect of bumetanide on the anion secretory current of IMCD (Fig. 1). In airways and intestinal epithelia, loop diuretics such as furosemide and bumetanide are potent inhibitors of the cAMPstimulated $\mathrm{I}_{\mathrm{SC}}$. A second difference is the magnitude of the response to cAMP in the absence of $\mathrm{HCO}_{3}^{-}$. In IMCD cells removal of $\mathrm{HCO}_{3}^{-}$markedly reduces the ability of cAMP to stimulate $\mathrm{I}_{\mathrm{SC}}$ (Fig. 2). In intestine and airway epithelia the presence or absence of $\mathrm{HCO}_{3}^{-}$does not alter the magnitude of the cAMP response (19). These characteristics of the IMCD make it unlikely that the basolateral membrane entry step for anion secretion is via the $\mathrm{Na}^{+} / \mathrm{K}^{+} / 2 \mathrm{Cl}^{-}$cotransporter. This conclusion is somewhat unexpected, since there is good evidence for such a transporter in freshly isolated rat IMCD cells (20).

Significance of $\mathrm{Cl}^{-}$secretion by the IMCD. The demonstration of active anion secretion by the IMCD is an unexpected development. It is well established that the collecting duct absorbs $\mathrm{Na}^{+}$and $\mathrm{Cl}^{-}$; secretion is not a generally recognized phenomenon. However, scrutiny of the literature reveals several hints that secretion by the distal nephron might be both demonstrable and physiologically important. The first hint comes from studies conducted on primary cultures of pig IMCD cells (21), in which a transient increase in $\mathrm{I}_{\mathrm{SC}}$ was demonstrated following bradykinin exposure. Recent preliminary data from a mouse IMCD cell line also suggest the presence of anion secretion (22). Evidence of the possible in vivo importance comes from data using microcatheterization of the IMCD of rats given an acute isotonic volume load. Using this approach, Sonnenberg (23) showed clear evidence of $\mathrm{Na}^{+}$and fluid secretion along the IMCD. The mechanism of this secretion has not been elucidated, but it is possible that the anion secretory pathway described here could play a role. In this regard, it seems possible that the increase in $\mathrm{Na}^{+}$and $\mathrm{Cl}^{-}$excretion that accompanies an increase in blood pressure ("pressure natriuresis") might have a tubular component as well as a hemodynamic one (24). If so, secretion by the collecting duct may play a role in that process.

$\mathrm{Cl}^{-}$secretion by the distal nephron has been documented in two other situations. Wingo (25) has demonstrated (active) $\mathrm{Cl}^{-}$secretion by isolated cortical collecting ducts dissected from rabbits fed a $\mathrm{K}^{+}$- and $\mathrm{HCO}_{3}^{-}$-rich diet. Schnermann et al. (26) have demonstrated $\mathrm{Cl}^{-}$secretion by the earliest portion of the rat distal convoluted tubule. A cAMP-induced $\mathrm{Cl}^{-}$-conductive pathway in the rabbit cortical collecting duct has been demonstrated by Schuster (27) using cable analysis. In addition to these data from intact tubules, there is evidence that CFTRlike $\mathrm{Cl}^{-}$channels are present in the apical membrane of distal nephron cells. $\mathrm{Cl}^{-}$channels with the appropriate single-channel characteristics have been identified in A6 cells (28), primary cultures of rabbit cortical collecting duct (29), and primary cultures of rabbit early distal convoluted tubule (30). We point out that other kinds of $\mathrm{Cl}^{-}$channels have been demonstrated in the apical membrane of distal nephron epithelial cells (28, 31 ). Thus, there is clear evidence that the distal nephron can secrete $\mathrm{Cl}^{-}$and that the CFTR might be involved in the process.

The present results should not be taken to indicate that activation of an apical membrane anion-conductive pathway will inevitably produce $\mathrm{Cl}^{-}$and fluid secretion. An example of the complexity of the interactions of activation of apical $\mathrm{Na}^{+}$ and $\mathrm{Cl}^{-}$channels has been recently demonstrated using $\mathrm{A} 6$ cells. It is well established that these cells have the capacity for electrogenic $\mathrm{Na}^{+}$absorption as well as $\mathrm{Cl}^{-}$secretion (32). Using maneuvers known to alter the permeability of apical $\mathrm{Na}^{+}$and $\mathrm{Cl}^{-}$channels, Verrey (33) showed that when $\mathrm{Cl}^{-}$channels were activated while $\mathrm{Na}^{+}$channels were closed, there was net $\mathrm{Cl}^{-}$ secretion. However, under (open-circuited) conditions when $\mathrm{Na}^{+}$channels were activated, activation of $\mathrm{Cl}^{-}$channels produced net $\mathrm{Cl}^{-}$absorption. Similar principles may operate in airway epithelia, which also have apical $\mathrm{Na}^{+}$and $\mathrm{Cl}^{-}$channels (34).

The reason that activation of apical membrane $\mathrm{Cl}^{-}$channels could effect either net secretion or absorption is that the electrochemical driving force for $\mathrm{Cl}^{-}$across the apical membrane under "normal" conditions is near 0 (29). The magnitude of the apical membrane voltage is a major determinant of the direction of the net $\mathrm{Cl}^{-}$movement. Activation of $\mathrm{Na}^{+}$channels, which depolarizes the apical membrane, shifts the driving force to favor $\mathrm{Cl}^{-}$absorption. When $\mathrm{Na}^{+}$channels are closed, the electrochemical gradient in short-circuited conditions favors $\mathrm{Cl}^{-}$secretion. Hence the present demonstration of anion secretion under conditions where $\mathrm{Na}^{+}$channels are inhibited and the epithelium is voltage clamped should not be interpreted to indicate that cAMP agonists will always induce $\left(\mathrm{Na}^{+}\right) \mathrm{Cl}^{-}$ secretion. 
The demonstration that the CFTR can be expressed in IMCD cells and that CAMP agonists can promote $\mathrm{Cl}^{-}$secretion raises the possibility that these regulatory processes might be involved in the generation of renal cysts. Recent work by Grantham and co-workers have demonstrated that the growth of cysts and the magnitude of fluid secretion can be enhanced by cAMP (3537 ). The mechanism of fluid secretion appears to involve an apical $\mathrm{Cl}^{-}$channel and a basolateral pathway for $\mathrm{Na}^{+}$and $\mathrm{Cl}^{-}$ entry (38). The extent to which the specific molecules responsible for anion secretion by these IMCD cells are involved in fluid secretion by renal cysts may be an interesting area for further study.

\section{Acknowledgments}

We appreciate the technical assistance of Bonnie Moses and Teresa Schmidt. Michael Dennis, Deanna Peterson, and Dr. Michael Welsh provided many helpful comments.

This work was supported in part by National Institutes of Health grant DK-25231, by a Merit Review grant from the Department of Veterans Affairs, and by a grant from the American Heart Association, Iowa chapter. K. A. Volk was a fellow of the American Heart Association, Iowa chapter.

\section{References}

1. Zeidel, M. L. 1993. Hormonal regulation of inner medullary collecting duct sodium transport. Am. J. Physiol. (Renal, Fluid Electrolyte Physiol.) 265:F159F173.

2. Husted, R. F., J. R. Laplace, and J. B. Stokes. 1990. Enhancement of electrogenic $\mathrm{Na}^{+}$transport across rat inner medullary collecting duct by glucocorticoid and by mineralcorticoid hormones. J. Clin. Invest. 86:498-506.

3. Laplace, J. R., R. F. Husted, and J. B. Stokes. 1992. Cellular responses to steroids in the enhancement of $\mathrm{Na}^{+}$transport by rat collecting duct cells in culture. Differences between glucocorticoid and mineralocorticoid hormones. J. Clin. In vest. 90:1370-1378.

4. Grenier, F. C., and W. L. Smith. 1978. Formation of 6-keto-PGF ${ }_{1}$ a by collecting tubule cells isolated from rabbit renal papillae. Prostaglandins. 16:759772.

5. Husted, R. F., M. Hayashi, and J. B. Stokes. 1988. Characteristics of papillary collecting duct cells in primary culture. Am. J. Physiol. (Renal, Fluid Electrolyte Physiol.) 255:F1160-F1169.

6. Chomczynski, P., and N. Sacchi. 1987. Single-step method of RNA isolation by acid guanidinium thiocyanate-phenol-chloroform extraction. Anal. Biochem. 162:156-159.

7. Trezise, A. E. O., C. Szpirer, and M. Buchwald. 1992. Localization of the gene encoding the cystic fibrosis transmembrane conductance regulator (CFTR) in the rat to chromosome 4 and implications for the evolution of mammalia chromosomes. Genomics. 14:869-874.

8. Hamati, H. F., E. L. Britton, and D. J. Carey. 1989. Inhibition of proteogly can synthesis alters extracellular matrix deposition, proliferation, and cytoskeletal organization of rat aortic smooth muscle cells in culture. J. Cell Biol. 108:24952505.

9. Keppler, D. O. R., J. F. M. Rudigier, and K. F. A. Decker. 1970. The trapping of uridine phosphate by D-galactosamine, D-glucosamine, and 2-deoxy-Dgalactose. A study on the mechanism of galactosamine hepatitis. Eur. J. Biochem. 17:246-253.

10. Matsuda, J. J., K. A. Volk, and E. F. Shibata. 1990. Calcium currents in isolated rabbit coronary arterial smooth muscle myocytes. J. Physiol. 427:657680.

1. McCann, J. D., M. Li, and M. J. Welsh. 1989. Identification and regulation of whole-cell chloride currents in airway epithelium. J. Gen. Physiol. 94:10151036.

12. Worrell, R. T., A. G. Butt, W. H. Cliff, and R. A. Frizzell. 1989. A volume-sensitive chloride conductance in human colonic cell line T84. Am. J. Physiol. Cell Physiol. 256:C1111-C1119.
13. Kleyman, T. R., and E. J. Cragoe. 1988. Amiloride and its analogs as tools in the study of ion transport. J. Membr. Biol. 105:1-21.

14. Anderson, M. P., D. N. Sheppard, H. A. Berger, and M. J. Welsh. 1992. Chloride channels in the apical membrane of normal and cystic fibrosis airway and intestinal epithelia. Am. J. Physiol. (Lung Cell. Mol. Physiol.) 263:L1-L14.

15. Sheppard, D. N., and M. J. Welsh. 1992. Effect of ATP-sensitive $\mathbf{K}^{+}$ channel regulators on cystic fibrosis transmembrane conductance regulator chloride currents. J. Gen. Physiol. 100:573-591.

16. Haas, M. 1989. Properties and diversity of $\left(\mathrm{Na}-\mathrm{K}-\mathrm{Cl}^{-}\right)$cotransporters. Annu. Rev. Physiol. 51:443-457.

17. Cabantchik, Z. I., and R. Greger. 1992. Chemical probes for anion transporters of mammalian cell membranes. Am. J. Physiol. Cell Physiol. 262:C803C827.

18. Tabcharani, J. A., W. Low, D. Elie, and J. W. Hanrahan. 1990. Lowconductance chloride channel activated by cAMP in the epithelial cell line $T_{84}$. Fed. Eur. Biochem. Soc. 270:157-164.

19. Welsh, M. J. 1987. Electrolyte transport by airway epithelia. Physiol. Rev. 67:1143-1183.

20. Grupp, C., I. Pavenstadt-Grupp, R. W. Grunewald, C. Bevan, J. B. Stokes, and $\mathrm{R}$. K. H. Kinne. 1989. A Na-K-Cl cotransporter in isolated rat papillary collecting duct cells. Kidney Int. 36:201-209.

21. Cuthbert, A. W., A. M. George, and L. MacVinish. 1985. Kinin effects on electrogenic ion transport in primary cultures of pig renal papillary collecting tubule cells. Am. J. Physiol. (Renal Fluid Electrolyte Physiol.) 249:F439-F447.

22. Kizer, N., B. Lewis, D. Vandorpe, W. B. Guggino, and B. A. Stanton. 1993. Vasopressin and cAMP stimulate electrogenic chloride secretion by an inner medullary collecting duct (IMCD) cell line isolated from a transgenic mouse. JASN 4:869 (abstract).

23. Sonnenberg, H. 1975. Secretion of salt and water into the medullary collecting duct of Ringer-infused rats. Am. J. Physiol. 228:565-568.

24. Romero, J. C., M. D. Bentley, P. M. Vanhoutte, and F. G. Knox. 1989 Intrarenal mechanisms that regulate sodium ecretion in relationship to changes in blood pressure. Mayo Clin. Proc. 64:1406-1424.

25. Wingo, C. S. 1989. Potassium secretion by the cortical collecting tubule effect of $\mathrm{Cl}$ gradients and ouabain. Am. J. Physiol. (Renal Fluid Electrolyte Physiol.) 256:F306-F313.

26. Schnermann, J., J. Briggs, and G. Schubert. 1982. In situ studies of the distal convoluted tubule in the rat. I. Evidence for $\mathrm{NaCl}$ secretion. Am. J. Physiol. (Renal Fluid Electrolyte Physiol.) 243:F160-F166.

27. Schuster, V. L. 1986. Cyclic adenosine monophosphate-stimulated anion transport in rabbit cortical collecting duct. Kinetics, stoichiometry, and conductive pathways. J. Clin. Invest. 78:1621-1630.

28. Marunaka, Y., and Eaton, D. C. 1990. Chloride channels in the apical membrane of a distal nephron A6 cell line. Am. J. Physiol. (Cell Physiol.) 258:C352-C368.

29. Ling, B. N. K. E. Kokko, and D. C. Eaton. 1994. Prostaglandin E activates clusters of apical $\mathrm{Cl}^{-}$channels in principal cells via a cyclic adenosine monophosphate-dependent pathway. J. Clin. Invest. 93:829-837.

30. Poncet, V., M. Tauc, M. Bidet, and P. Poujeol. 1994. Chloride channel in the apical membrane of primary cultures of rabbit distal bright convoluted tubule. Am. J. Physiol. (Renal Fluid Electrolyte Physiol.) 266:F543-F553.

31. Light, D. B., E. M. Schwiebert, G. Fejes-Toth, A. Naray-Fejes-Toth K. H. Karlson, F. V. McCann, and B. A. Stanton. 1990. Chloride channels in the apical membrane of cortical collecting duct cells. Am. J. Physiol. (Renal Fluid Electrolyte Physiol.) 258:F273-F280.

32. Chalfant, M. L., B. Coupaye-Gerard, and T. R. Kleyman. 1993. Distinct regulation of $\mathrm{Na}^{+}$reabsorption and $\mathrm{Cl}^{-}$secretion by arginine vasopressin in the amphibian cell line A6. Am. J. Physiol. Cell Physiol. 264:C1480-C1488.

33. Verrey, F. 1994. Antidiuretic hormone action in A6 cells: effect on apical and $\mathrm{Cl}$ and $\mathrm{Na}$ conductances and synergism with aldosterone for $\mathrm{NaCl}$ reabsorption. J. Membr. Biol. 138:65-76.

34. Smith, J. J., and M. J. Welsh. 1993. Fluid and electrolyte transport by cultured human airway epithelia. J. Clin. Invest. 91:1590-1597.

35. Mangoo-Karim, R., M. Uchic, C. Lechene, and J. J. Grantham. 1989. Renal epithelial cyst formation and enlargement in vitro: dependence on cAMP. Proc. Natl. Acad. Sci. USA. 86:6007-6011.

36. Ye, M., and J. J. Grantham. 1993. The secretion of fluid by renal cysts from patients with autosomal dominant polycystic kidney disease. N. Engl. J. Med. 329:310-313.

37. Neufeld, T. K., D. Douglass, M. Grant, M. Ye, F. Silva, T. Nadasdy, and J. J. Grantham. 1992. In vitro formation and expansion of cysts derived from human renal cortex epithelial cells. Kidney Int. 41:1222-1236.

38. Grantham, J. J. 1993. Fluid secretion, cellular proliferation, and the pathogenesis of renal epithelial cysts. J. Am. Soc. Nephrol. 3:1843-1857. 